\title{
Adult-to-adult living donor liver transplantation
}

\author{
Shimul A Shah MD, Gary A Levy MD, Lesley D Adcock MD, Gary Gallagher RN, David R Grant MD
}

\begin{abstract}
SA Shah, GA Levy, LD Adcock, G Gallagher, DR Grant. Adult-to-adult living donor liver transplantation. Can J Gastroenterol 2006;20(5):339-343.

The present review outlines the principles of living donor liver transplantation, donor workup, procedure and outcomes. Living donation offers a solution to the growing gap between the need for liver transplants and the limited availability of deceased donor organs. With a multidisciplinary team focused on donor safety and experienced surgeons capable of performing complex resection/reconstruction procedures, donor morbidity is low and recipient outcomes are comparable with results of deceased donor transplantation.
\end{abstract}

Key Words: Cirrhosis; Liver transplantation; Living donor; Morbidity; Right hepatectomy

\section{Transplantation hépatique à donneur vivant d'adulte à adulte}

\begin{abstract}
Le présent article de synthèse rappelle les principes de la transplantation hépatique à donneur vivant et décrit la préparation du donneur, les étapes de l'intervention et le pronostic. La greffe de foie provenant d'un donneur vivant offre une solution à la pénurie grandissante d'organes pour les transplantations et à la difficulté d'obtenir des organes provenant de cadavres. Grâce à une équipe pluridisciplinaire déterminée à assurer la sécurité du donneur et à des chirurgiens expérimentés et capables de réaliser de complexes interventions de résection et de reconstruction, la morbidité est faible chez les donneurs et l'issue du traitement chez les receveurs se compare aux résultats obtenus avec les greffons provenant de cadavres.
\end{abstract}

More than 2000 LDLTs (right and left lobe grafts) have been performed throughout the world. There have been a number of deaths after $\operatorname{LD}(5,6)$ and the risk of death is estimated to be $0.2 \%$ to $0.5 \%$ with left lobe donation and $0.3 \%$ to $1 \%$ with right lobe donation. Ethical concerns have been raised and the long-term success of right lobe donor hepatectomy will depend on the safety and efficiency of the procedure.

Enthusiasm in the United States has waned since 2001 after the death of a living donor in New York City, New York (5). This is despite relatively stagnant DD volumes and increasing number of patients on the waiting list. In 2004, roughly 350 LDLTs were performed in the United States; this number has remained relatively constant since 2002. Proper documentation of complications, uniform standards and dedicated LD protocols will be necessary to monitor progress and growth in LDLT.

The shortage of donor organs is more acute in Canada than in the United States due to our much lower DD rates. Although we are still in the early stages of experience with LDLT in Canada, there is already evidence of a positive impact (Figure 2). In Toronto, where the donor shortage is particularly acute, LDLT now accounts for $40 \%$ of total adult LT volumes (Figure 3).

LD has several potential advantages. The surgery can be performed at an optimal time before the recipient's health deteriorates unduly; furthermore, the recipient receives a high-quality organ due to thorough donor evaluation and shorter cold ischemic time. The donor has a unique opportunity to restore good health to a close friend or family member $(7,8)$. Because the liver regenerates, long-term

Multiorgan Transplant Program, University Health Network, University of Toronto, Toronto, Ontario

Correspondence: Dr David R Grant, Department of Surgery, Toronto General Hospital, University Health Network,

University of Toronto, 585 University Avenue, 11C-1244, Toronto, Ontario M5G 2N2. Telephone 416-340-5230, fax 416-340-5242,

e-mail david.grant@uhn.on.ca

Received for publication January 15, 2006. Accepted January 16, 2006 


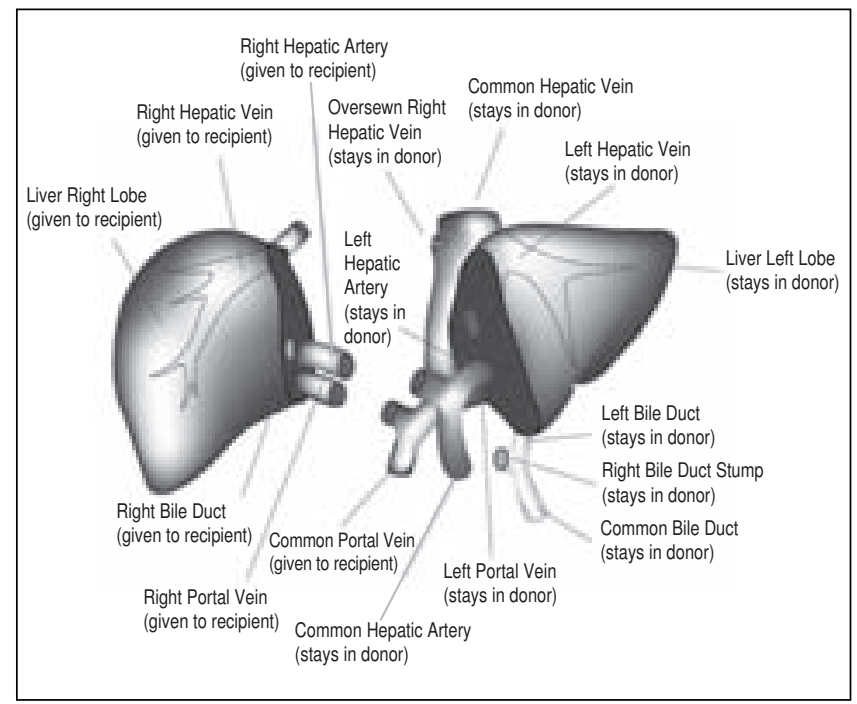

Figure 1) Anatomy of right lobe, living donor hepatectomy. Reproduced/adapted from reference 28

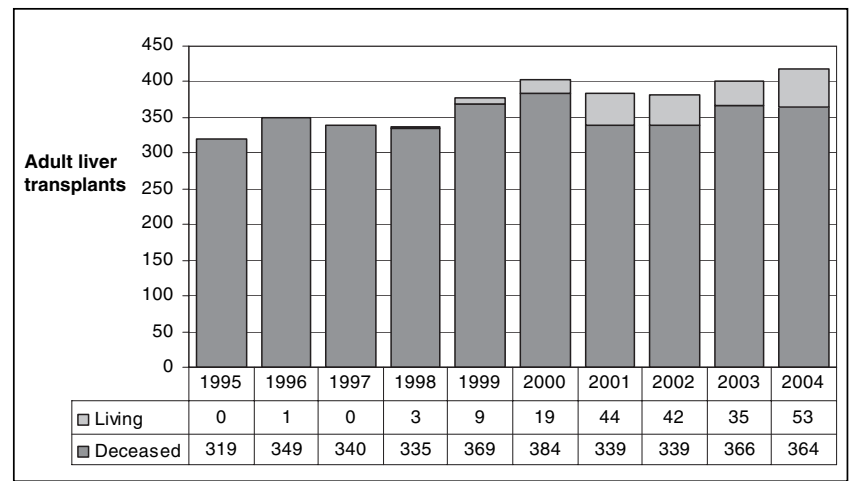

Figure 2) Ratio of living donor liver transplants to deceased donor liver transplants in adults living in Canada from 1995 to 2004

liver function is normal in both the donor and the recipient, provided there are no complications.

The challenge of LDLT is to perform the donor operation safely without compromising the recipient outcomes. The risk of donor death is estimated to be $0.2 \%$ for left lateral segment donation and $0.5 \%$ for right lobe donation, so the emphasis on donor safety is of paramount importance in this procedure. The rest of the present article will review the assessment process, surgery, outcomes and future prospects of LDLT.

\section{PRINCIPLES GUIDING THE LIVE LIVER DONOR ASSESSMENT}

LD must be voluntary and altruistic. Donors must be between 18 and 60 years of age and be capable of providing informed consent. If more than one potential donor volunteers, the donors are usually investigated according to the date of receipt of the health questionnaire and blood type confirmation (unless the intended recipient and donors meet and collectively instruct the LT centre of a different preference for the workup order).

It is the donor's responsibility to communicate to the team if there are any concerns or issues that need to be addressed during the assessment. If the screening questionnaire reveals major health issues, the donor may be asked to

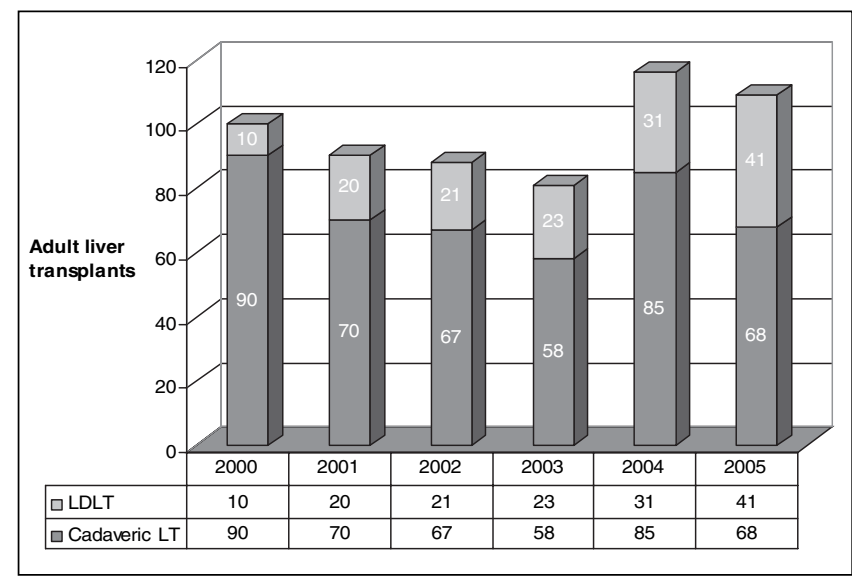

Figure 3) Adult liver transplant (LT) volumes in Toronto. LDLT Living donor liver transplantation

provide a letter of support from his/her attending doctor before starting the workup.

The duration of workup is determined by the availability of health care resources, the donor's schedule and the complexity of the donor's health issues. We review all potential donors in workup at a multidisciplinary conference that includes surgeons, medical doctors, nurses, social workers and transplant coordinators. Any concerns are discussed in an open manner during this meeting.

The intended recipient must consent to LD; some patients are reluctant to do this because of concerns about potential harm to the donor. At our centre, recipients of LD grafts must satisfy the criteria for LT or meet expanded criteria that are within predefined protocols or clinical trials. Recipients of $\mathrm{LD}$ grafts must consent to sharing information about the cause of the recipient's liver disease, the anticipated rate of success with LDLT and the potential for disease recurrence with the donor.

Potential recipients for $\mathrm{LD}$ remain on the DD waiting list while the transplant workup is in progress. The opportunity for LD does not affect the status of the recipient on the DD list. DD organs are offered according to the standard Canadian allocation algorithm, irrespective of whether the recipient has a potential LD.

To proceed with $\mathrm{LD}$, there must be an agreement among the donor, recipient and the medical team that this surgery is appropriate. We will not perform LDLT if the medical and surgical team believe that the potential for harm outweighs the benefits. Unusual ethical issues may be taken to the Transplant Ethics Committee for review and advice. Because the physicians and members of the transplant team also act as moral agents, we believe that the final decision to perform the LDLT must rest with the transplant doctors. If the team decides that $\mathrm{LD}$ is inappropriate, we routinely offer to arrange referrals to other programs for second opinions.

Donor safety is the main priority guiding the timing of surgery. It is important to have a well-rested and experienced surgical team for LT to maximize safety. Thus, LD is not performed as an emergency procedure at our centre.

Costs and long-term consequences of LD remains a controversial issue in the transplant community. In Ontario, the Ontario Ministry of Health and Long-Term Care (Ontario 
Health Insurance Plan [OHIP]) supports the direct costs of liver donation. However, neither OHIP nor the hospital will compensate donors for indirect costs such as time lost from work, travel expenses or outpatient mediation costs. If a donor travels from another country to donate; only assessment tests, physician and hospital costs are covered by the recipient's OHIP. Travel costs are not covered nor are the costs of any investigations or follow-up performed in their country of origin. At the University of Toronto, we are attempting to follow all donors and recipients for up to 10 years to monitor long-term safety.

\section{LIVING DONOR ASSESSMENT}

All living donors are deemed suitable for surgery after completing an evaluation process that includes an initial healthscreening survey, blood tests, viral serology, imaging studies and medical and psychiatric assessments by health care professionals independent of the transplantation team. These consultations provide potential donors with an opportunity to confidentially opt out or decline liver donation for medical, social or personal reasons without having to provide an explanation to the intended recipient or to the transplant team.

Routine liver biopsy before LD remains controversial; we have elected to perform liver biopsy selectively in patients in whom liver steatosis is suspected and in those with serum liver enzyme abnormalities (9). Donors with a body mass index greater than $35 \mathrm{~kg} / \mathrm{m}^{2}$ are not evaluated until they have completed a successful weight loss program. Absolute exclusion criteria include any underlying medical condition that is considered to increase the risk for complications, $\mathrm{ABO}$ incompatibility, positive hepatitis serology, underlying liver disease, inadequate graft size, steatosis greater than $10 \%$ and abnormal biliary anatomy (eg, branches to left lobe arising from right duct).

Triphasic computerized tomography is performed to assess arterial and venous anatomy; to assess whether the middle hepatic vein should stay in the donor or the recipient; and to estimate the volume of the whole liver, right lobe and remaining liver using OSIRIS imaging software (Digital Imaging Unit, University Hospital of Geneva, Switzerland). The liver resection plane is assessed to ensure that the residual liver weight to total liver weight ratio would be $30 \%$ or greater. The estimated graft-to-recipient weight ratio is calculated by dividing the volume of the right lobe by the recipient's weight; a ratio of at least $0.8 \%$ is considered acceptable. Magnetic resonance cholangiography has been used to assess biliary anatomy since $2001(10,11)$.

A multistep consent process involving two different surgeons on separate occasions is used, during which the operative procedure and potential complications are described in detail. Donors are informed that the risk of morbidity and mortality is $40 \%$ and $0.5 \%$, respectively. Donors are supported in whichever decision they make. The assessment for $\mathrm{LD}$ is a dynamic process. At any stage, the potential donor or the health care team may decide that it is not suitable to proceed with liver donation.

Currently, only approximately $20 \%$ of donors who indicate an interest in LD actually undergo the procedure. Between April 2000 and December 2005, 554 patients were evaluated for liver donation at the Toronto General Hospital (Toronto, Ontario); during this time period, 166 (30\%) of these patients underwent hepatectomy. The common causes of dropout or refusal after preliminary evaluation at our centre are listed in Table 1.
TABLE 1

Evaluation of dropouts or refusals for living donation at the University of Toronto, Toronto, Ontario

\begin{tabular}{lcr}
\hline Reason & $\mathbf{n}$ & $\%$ \\
\hline Under evaluation or underwent living donation & 201 & 36 \\
Donor decision & 65 & 12 \\
Cadaveric transplant for recipient & 43 & 8 \\
Alternate donor selected & 34 & 6 \\
Donor unsuitable & 32 & 6 \\
Recipient medically unsuitable for transplant & 27 & 5 \\
Recipient died before transplant & 23 & 4 \\
Size discrepancy & 22 & 4 \\
Liver steatosis & 18 & 3 \\
Donor anatomy unsuitable & 14 & 3 \\
Other & 75 & 13 \\
Total & 554 & 100 \\
\hline
\end{tabular}

RIGHT LOBE LIVING DONOR HEPATECTOMY

Patients donated one to two units of autologous blood within one month of the planned surgery date. Prophylactic antimicrobial (cefazolin, metronidazole) and anti-deep vein thrombosis (DVT; heparin $5000 \mathrm{U}$ subcutaneously) therapy was initiated immediately before surgery. Pneumatic compression stockings were used routinely over the past year to reduce the risk of DVT. Epidural analgesic delivery was offered to all donors.

Surgery was performed through a right subcostal hockeystick incision (12). An intraoperative cholangiogram with fluoroscopy was performed first to verify biliary anatomy; surgery was aborted in four donors $(3 \%)$ because of abnormal biliary anatomy which was only detected by cholangiography. The right hepatic artery and right portal vein(s) were mobilized. The right lobe was mobilized off the inferior vena cava; the right hepatic vein and accessory right hepatic veins exceeding $8 \mathrm{~mm}$ in diameter were preserved for revascularization in the recipient. The Hydro-Jet Dissector (ERBE, Germany) and the Cavitron Ultrasonic Aspirator (CUSA Excel, Valleylab, USA) were used to transect the liver parenchyma along the plane of the middle hepatic vein which was retrieved with the graft when it provided the dominant venous drainage to the right lobe. A red blood cell scavenging device was used routinely. A cholangiogram was performed at the end of the procedure.

Donors were managed in an intensive care step-down unit for the first $48 \mathrm{~h}$ and then in a regular surgical ward. Complete blood counts, coagulation profile and serum liver tests were monitored daily. Patients were given parenteral magnesium and phosphate infusions routinely until tolerating diet and then were transitioned and discharged home on oral magnesium and phosphate as required (13-15). DVT prophylaxis continued with heparin $5000 \mathrm{U}$ subcutaneously and sequential compression stockings while in hospital and with low molecular weight heparin (dalteparin sodium injection; Pharmacia, Canada) 5000 U subcutaneously daily for six weeks after discharge. All patients under went routine Doppler ultrasound of the abdomen on the third postoperative day to assess vessel integrity and flow. Donors were followed up with routine laboratory investigations and abdominal ultrasound at one month, three months, six months and then annually after surgery. 
TABLE 2

Total complications of right lobe living donor liver transplantation classified by severity at the University of Toronto, Toronto, Ontario

\begin{tabular}{lcc}
\hline Complication $^{\star}$ & $\mathbf{n}(\%)$ & $\begin{array}{c}\text { Operative } \\
\text { intervention (n) }\end{array}$ \\
\hline $\begin{array}{l}\text { Grade I } \\
\text { Urinary tract infection/ }\end{array}$ & \\
$\quad$ recatheterization & $4(4)$ & - \\
Arrythmia & $1(1)$ & - \\
$\quad$ Depression & $2(2)$ & - \\
Grade II & & Operative (9) \\
Incisional hernia or repair & $9(9)$ & - \\
Wound infection & $5(5)$ & Operative (4) \\
Bleeding (reoperation) & $4(4)$ & Endoscopic (4) \\
Subphrenic/pleural collection & $4(4)$ & - \\
Bile leak & $3(3)$ & Endoscopic (3) \\
Pulmonary emboli & $2(2)$ & - \\
Pneumonia & $2(2)$ & - \\
Partial bowel obstruction & $1(1)$ & \\
Grade III & & \\
None & & \\
Grade IV & & \\
None & & \\
Total & $37(37)$ & $20(20 \%)$ \\
\hline
\end{tabular}

${ }^{*}$ Grade of complication determined by Clavien's classification (27)

\section{DONOR OUTCOMES}

A crude complication rate of $31 \%$ (54 events in 174 donors) was reported in a review of 12 studies of right lobe liver donors (16). The overall complication rate in our first 101 cases in Toronto was 37\% (Table 2) (3). No patient had suffered life-threatening organ dysfunction or residual disability. The complication rate during the first 30 days postoperatively was significantly lower than in the later one-half of our experience. All donors are currently alive and well, and have returned to their normal daily activities.

The earliest most common serious complication (3) was postoperative bleeding which occurred in four patients on postoperative day 1 . All were taken to the operating room. The source of bleeding in all four cases was a small artery in the hilar plate; this complication has since been avoided because we started routinely oversewing this area.

Other early complications included bile leak (3\%), subphrenic or pleural collections requiring drainage $(3 \%)$ and pulmonary embolus (1\%). Two of the three bile leaks were treated with endoscopic retrograde cholangiopancreatography, stent placement and papillotomy; the other was treated with a percutaneous drain. Temporary percutaneous drainage of a subphrenic or pleural effusion was required in three patients. Three patients required reclosure of a partial fascial dehiscence located at the junction of the midline and subcostal portion of the incision. Late complications have included incisional hernia $(\mathrm{n}=6)$, pneumonia $(\mathrm{n}=2)$, late pulmonary embolism $(\mathrm{n}=2)$ and partial bowel obstruction $(\mathrm{n}=1)$.

\section{RECIPIENT OUTCOMES}

LDLT provides an option to avoid the risk of death while waiting for a DDLT. One-year survival after LDLT is similar

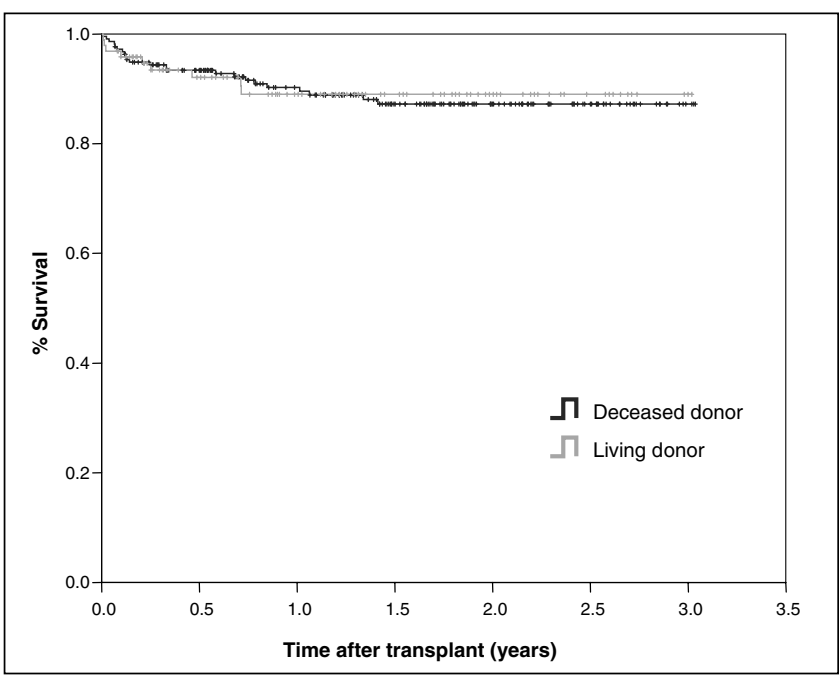

Figure 4) Cumulative survival from 2003-2005 of patients from the time of transplant who underwent either deceased donor liver transplants $(n=146)$ or living donor liver transplants $(n=81)$

to DDLT. However, if one compares survival of patients from the time of listing who are waiting for a DDLT or who undergo DDLT with patients who undergo LDLT, there is a survival advantage as early as 12 months (Figure 4). Reported rates of survival after both LDLT and DDLT is between $86 \%$ to $88 \%$ $(1,17-20)$. Survival statistics for LDLT should be interpreted with caution; in many cases, patients are selected with the best chance of favourable outcome, minimal cirrhosis or portal hypertension, and shorter waiting times. Direct comparisons between DD and LDLT can only be made if the degree of liver disease is stratified and accounted for in the analyses (eg, Model for End-Stage Liver Disease).

Specific problems inherent to LDLT comprise a spectrum of complications that are still poorly understood. There has been a higher rate of bile duct complications in live donor recipients compared with DD recipients (approximately 20\% versus approximately 5\%) but most of these complications have been resolved with nonsurgical management $(19,21-24)$; these problems include bile leaks from the cut surface of the transected liver, biliary strictures and anastomotic leaks. Hepatic artery thrombosis is also more common in LDLT, with rates of $1 \%$ to $7 \%(20,25,26)$. Small-for-size syndrome is an important entity with an unknown frequency and clinical course in LDLT. Its mechanism is poorly understood because it can occur despite adequate volume calculations and body weight assessments pre-LT. Graft dysfunction of suboptimally drained segments (usually segments 5 and 8) can account for this debilitating syndrome. We prefer a graft-to-recipient ratio of greater than 0.8 in all LDLT and believe that additional venous drainage through the middle hepatic vein may alleviate congestion of the graft in the medial sector and lead to better function (2).

\section{FUTURE PROSPECTS}

Balancing donor-risk relative to the recipient outcome is an ongoing task in the evolution of LDLT. Other important issues that require further study include: hypercoaguable states in donors after hepatectomy, small-for-size grafts, venous outflow 
obstruction, hepatic artery thrombosis, liver steatosis and timing. As allocation systems evolve to ensure that limited organs benefit those patients at a greatest risk of death (eg, Model for End-Stage Liver Disease), LDLT may become an avenue to provide a liver graft to someone who would not ordinarily qualify for a DD organ.

\section{CONCLUSIONS}

LDLT is an effective life-saving procedure for patients with end-stage liver disease. We predict that the demand for right lobe LDLT in North America, specifically Canada, will continue to increase because of the critical shortage of donor organs. Although LDLT has been performed with low morbidity at high-volume transplant centres, it remains a daunting operation with unique surgical and ethical challenges. Comprehensive documentation of complications and long-term follow-up will continue to be required to define donor-risk and to advance the field.

ACKNOWLEDGEMENTS: The authors thank Robert Smith for data and statistical support.

\section{REFERENCES}

1. Trotter JF, Wachs M, Everson GT, Kam I. Adult-to-adult transplantation of the right hepatic lobe from a living donor. N Engl J Med 2002;346:1074-82.

2. Cattral MS, Molinari M, Vollmer CM Jr, et al. Living-donor right hepatectomy with or without inclusion of middle hepatic vein: Comparison of morbidity and outcome in 56 patients. Am J Transplant 2004:4:751-7.

3. Shah SA, Grant DR, Greig PD, et al. Analysis and outcomes of right lobe hepatectomy in 101 consecutive living donors. Am J Transplant 2005;5:2764-9.

4. Strong RW, Lynch SV, Ong TH, Matsunami H, Koido Y, Balderson GA. Successful liver transplantation from a living donor to her son. N Engl J Med 1990;322:1505-7.

5. Miller C, Florman S, Kim-Schluger L, et al. Fulminant and fatal gas gangrene of the stomach in a healthy live liver donor. Liver Transpl 2004;10:1315-9.

6. Broelsch CE, Frilling A, Testa G, et al. Early and late complications in the recipient of an adult living donor liver. Liver Transpl 2003;9(Suppl 2):50-3.

7. Broelsch CE, Testa G, Alexandrou A, Malago M. Living related liver transplantation: Medical and social aspects of a controversial therapy. Gut 2002;50:143-5.

8. Karliova M, Malago M, Valentin-Gamazo C, et al. Living-related liver transplantation from the view of the donor: A 1-year follow-up survey. Transplantation 2002;73:1799-804.

9. Nadalin S, Malago M, Valentin-Gamazo C, et al. Preoperative donor liver biopsy for adult living donor liver transplantation: Risks and benefits. Liver Transpl 2005;11:980-6.

10. Kim RD, Sakamoto S, Haider MA, et al. Role of magnetic resonance cholangiography in assessing biliary anatomy in right lobe living donors. Transplantation 2005;79:1417-21.
11. Macdonald DB, Haider MA, Khalili K, et al. Relationship between vascular and biliary anatomy in living liver donors. Am J Roentgenol 2005;185:247-52.

12. Dixon E, Vollmer CM Jr, Sahajpal A, et al. An aggressive surgical approach leads to improved survival in patients with gallbladder cancer: A 12-year study at a North American Center. Ann Surg 2005;241:385-94.

13. Pomposelli JJ, Pomfret EA, Burns DL, et al. Life-threatening hypophosphatemia after right hepatic lobectomy for live donor adult liver transplantation. Liver Transpl 2001;7:637-42.

14. Tan HP, Marcos A. Hypophosphatemia and the live liver donor. Transplantation 2005;79:258.

15. Tan HP, Madeb R, Kovach SJ, et al. Hypophosphatemia after 95 right-lobe living-donor hepatectomies for liver transplantation is not a significant source of morbidity. Transplantation 2003;76:1085-8.

16. Beavers KL, Sandler RS, Shrestha R. Donor morbidity associated with right lobectomy for living donor liver transplantation to adult recipients: A systematic review. Liver Transpl 2002;8:110-7.

17. Marcos A, Fisher RA, Ham JM, et al. Selection and outcome of living donors for adult to adult right lobe transplantation. Transplantation 2000;69:2410-5.

18. Maluf DG, Stravitz RT, Cotterell AH, et al. Adult living donor versus deceased donor liver transplantation: A 6-year single center experience. Am J Transplant 2005;5:149-56.

19. Olthoff KM, Merion RM, Ghobrial RM, et al. Outcomes of 385 adult-to-adult living donor liver transplant recipients: A report from the A2ALL Consortium. Ann Surg 2005;242:314-23.

20. Malago M, Testa G, Frilling A, et al. Right living donor liver transplantation: An option for adult patients: Single institution experience with 74 patients. Ann Surg 2003;238:853-62.

21. Testa G, Malago M, Valentin-Gamazo C, Lindell G, Broelsch CE. Biliary anastomosis in living related liver transplantation using the right liver lobe: Techniques and complications. Liver Transpl 2000;6:710-4.

22. Millis JM, Cronin DC, Brady LM, et al. Primary living-donor liver transplantation at the University of Chicago: Technical aspects of the first 104 recipients. Ann Surg 2000;232:104-11.

23. Gondolesi GE, Varotti G, Florman SS, et al. Biliary complications in 96 consecutive right lobe living donor transplant recipients. Transplantation 2004;77:1842-8.

24. Hanto DW, Fishbein TM, Pinson CW, et al. Liver and intestine transplantation: Summary analysis, 1994-2003. Am J Transplant 2005;5:916-33.

25. Marcos A, Killackey M, Orloff MS, Mieles L, Bozorgzadeh A, Tan HP. Hepatic arterial reconstruction in 95 adult right lobe living donor liver transplants: Evolution of anastomotic technique. Liver Transpl 2003;9:570-4.

26. Tan HP, Marcos A. Hepatic arterial anatomy for right liver procurement from living donors. Liver Transpl 2004;10:134-5.

27. Clavien PA, Camargo CA Jr, Croxford R, Langer B, Levy GA, Greig PD. Definition and classification of negative outcomes in solid organ transplantation. Application in liver transplantation. Ann Surg 1994;220:109-20.

28. Gill JS. Canadian Organ Replacement Register preliminary report, Canadian Institute for Health Information. Canadian Society for Telehealth annual meeting, Alberta, 2005. 


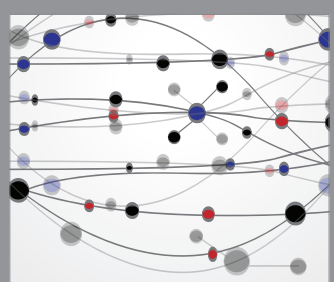

The Scientific World Journal
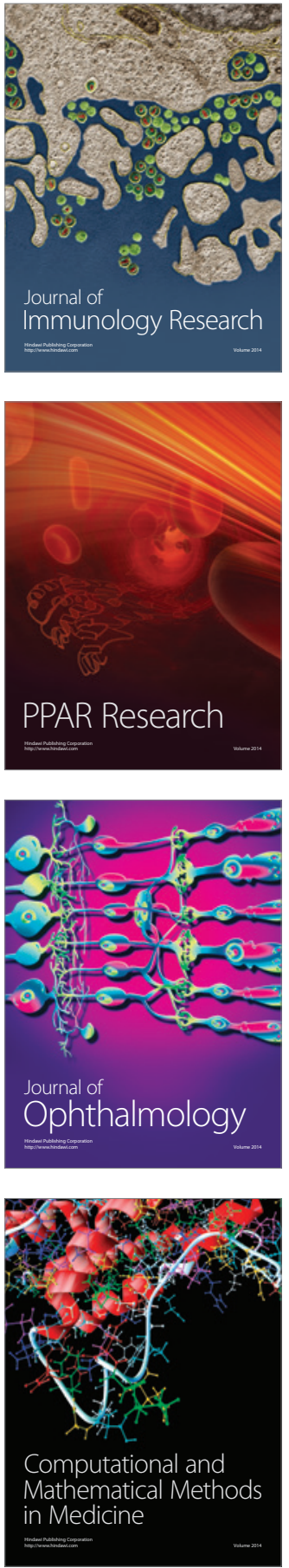

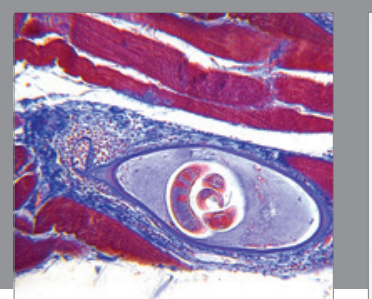

Gastroenterology Research and Practice

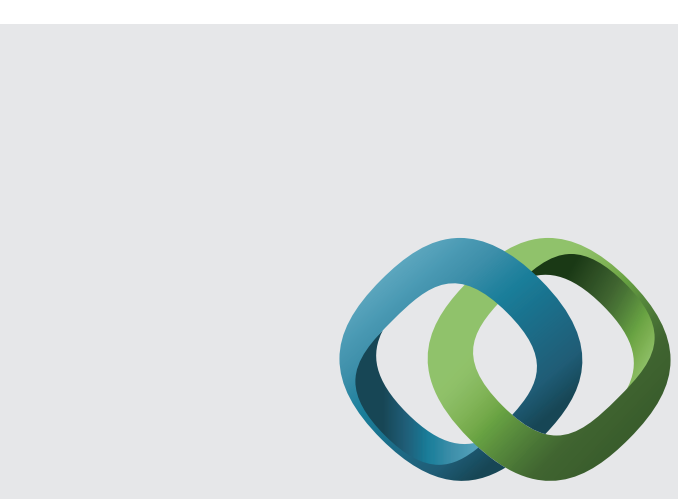

\section{Hindawi}

Submit your manuscripts at

http://www.hindawi.com
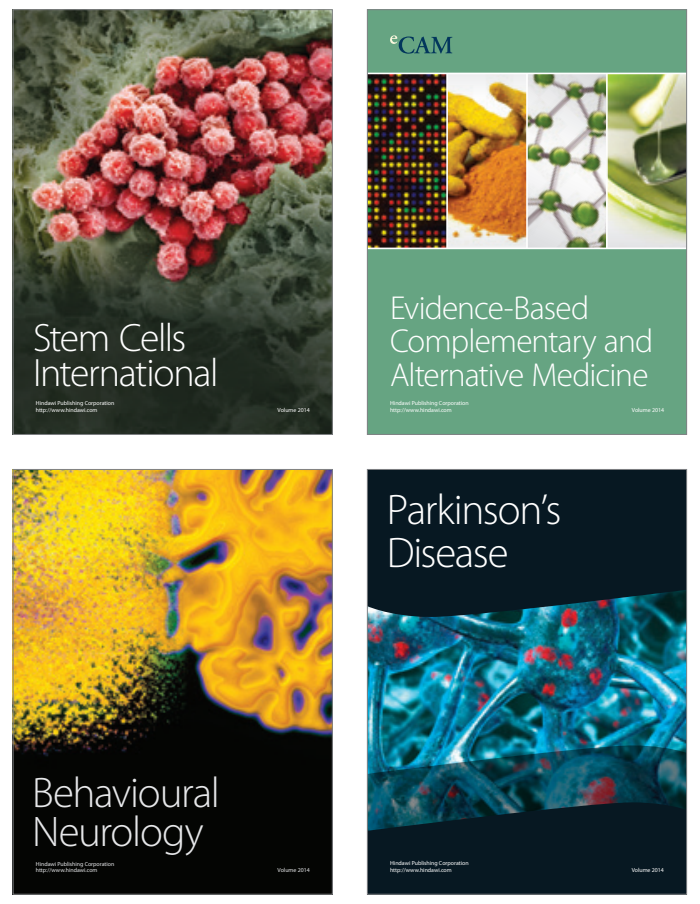
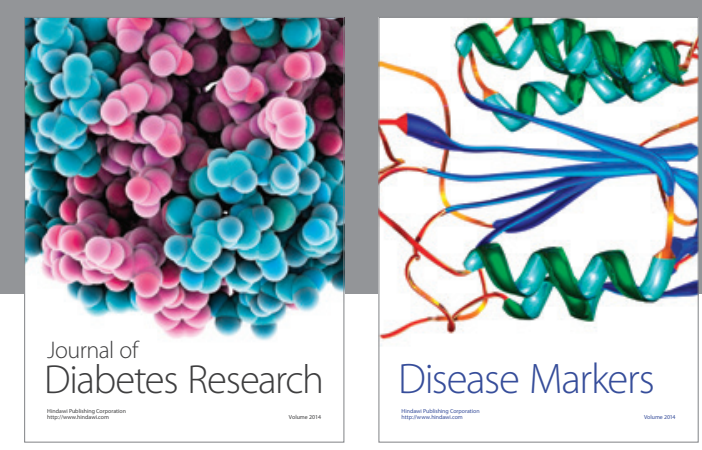

Disease Markers
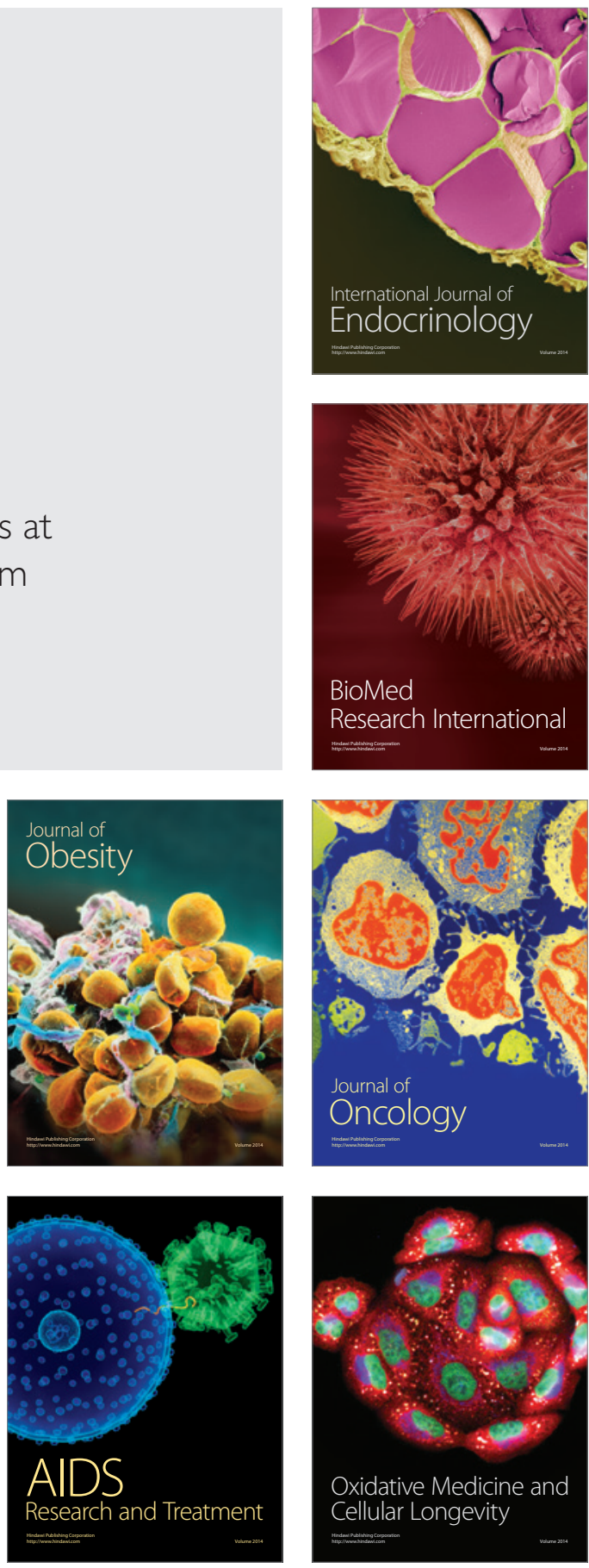